Europe's Journal of Psychology, 7(4), pp. 697-715

www.ejop.org

\title{
Turkish adaptation, validity, and reliability of The Domestic Violence Coping Self-Efficacy (DV-CSE) measure
}

\section{Orkide Akpınar}

Ege University, İmir

\begin{abstract}
Domestic violence is a traumatic experience faced primarily by women all over the world. Thus, ways in which victims of domestic violence cope with the stress caused by violence emerge as in important area of inquiry. Calling attention to the issue, Charles $C$. Benight, Alexandra S. Harding-Taylor, Amanda M. Midboe and Robert L. Durham developed the DV-CSE scale in 2004. The DV-CSE scale aims to measure the coping self efficacy of female victims of domestic violence following the latest attack, and is used in clinics in the US that provide support to victims of violence who have suffered physical or psychological damage. In Turkey, where one in every three women is a victim of domestic violence, there are no studies on the subject. This present study represents the adaptation of the DV-CSE scale to Turkish and comprises validity and reliability analyses. The sample of the study consisted of 258 women who applied to various institutions in and around Izmir due to domestic violence. All of these women had faced some type of domestic violence within the previous six months (physical, sexual, emotional or economic). Following the completion of the pre-adaptation study, exploratory and confirmatory factor analyses were conducted to examine the validity of the measure. To investigate reliability, Cronbach's alpha coefficient was used. The other method used to examine the reliability of the measure was structural reliability calculation. The analyses conducted showed that the DV-CSE-T (Turkish form) is a uni-dimensional and highly reliable scale for measuring levels of domestic violence coping self efficacy.
\end{abstract}

Keywords: Domestic violence coping self-efficacy measure, violence, domestic violence against women, coping self-efficacy, cognitive schemes.

It is known that domestic violence against women is a pervasive, traumatic experience in Turkey, as well as in other parts of the world (Study on Domestic 
Violence Against Women in Turkey, 2008; Damka, 2009). Yet, only in the last 20 years has domestic violence been the subject of academic studies (Altınay \& Arat, 2008), very few of these are on coping with domestic violence, and to the best of our knowledge, none focus on domestic violence coping self-efficacy. Considering this gap in the literature, the aim of this study is to examine women's domestic violence coping self-efficacy in Turkey by adapting the DV-CSE measure to Turkish, as a firsttime effort.

The World Health Organization defines violence as "the intentional use of physical force or power, threatened or actual, against oneself, another person, or against a group or community, that either results in or has a high likelihood of resulting in injury, death, psychological harm, maldevelopment or deprivation" (WHO, 2002, p. 5). A more comprehensive definition of violence would include, besides intentional and physical harm, verbal and psychological pressure as well. In this definition, violence refers to all sorts of behavior that restrict the enjoyment of freedoms and rights. Violence may emerge as a result of many factors at individual, inter-individual, family and societal levels.

Domestic violence can be defined as violent behavior displayed by one person against another that aims to coerce, humiliate, or punish the victim, or serves as a show of force or discharge of anger or tension for the perpetrator (Heise, 1993). The International Council of Nurses (2001) defines domestic violence as "a process whereby physical or emotional harm is done as a result of physical or sexual violence exerted by at least one family member against another or others" (International Council of Nurses, ICN, 2001, p. 9). Domestic violence usually starts with a marked tension in relations between family members and threats, and emerges in the form of the physical and emotional abuse of the children, child neglect, elderly neglect, and wife-beating. In inter-spousal violence, men are usually the perpetrators and women the victims of violence (WHO, 2002).

The World Health Organization found, in 48 studies covering all the world's population, that $10 \%$ to $69 \%$ of women have suffered physical violence from their spouses or partners (WHO, 2002). According to a 2004 report by Amnesty International, based on data from the United Nations, the World Health Organization, various governments and non-governmental organizations, at least one in every three women in the world, i.e., close to one billion women, has been the victim of beatings, forced sexual encounters, or some other form of abuse at some point in their lives, usually by a family member or someone they know (Amnesty International, 2004). The first studies on domestic violence against women 
in Turkey were conducted about 20 years ago (Altınay \& Arat, 2008). According to data reported in a study on domestic violence against women in Turkey (2008), 39\% of women have been victims of physical violence, $15 \%$ have been victims of sexual violence, and $44 \%$ have been victims of emotional violence by their spouses or partners at some point in their lives.

It is notable that women of all ages, cultures, statuses, levels of education and environments are subject to one or multiple forms of violence (physical, psychological, sexual, and economic, among others) (WHO, 2002; Study on Domestic Violence Against Women in Turkey, 2008). Thus, in recent years violence against women has started to be considered by WHO not as something that should remain private, but as a public health issue that needs to be dealt with, and as a violation of human rights. In other words, domestic violence against women today means the restriction of women's rights to live and feel secure, to have a high level of physical and mental health, and to participate in education, work life, and social life (WHO, 2002). This, in turn, is known to have detrimental effects on the physical and psychological health and the social lives of women who have been victims of violence (WHO, 2002; Damka, 2009).

The physical effects of violence on women are visible to the eye, but the effects on the psychological health of women, are not. Violence harms a woman's psyche; depression, high levels of anxiety, suicidal thoughts, psychosomatic illnesses and post-traumatic stress disorder (PTSD) are frequently seen among women who are psychologically sensitive (Clements, Sabourin and Spiby, 2004; Perez, Castano \& Lozano, 2007; Korkut-Owen and Owen, 2008; Cieslak, Benight \& Caden, 2008; Damka, 2009). For example, Gleason (1993) found that $40 \%$ of women who stay in women's shelters, and $31 \%$ of female victims of violence who do not stay in shelters suffer from PTSD. Saunders (1994) found that $60 \%$ of a sample which consisted of women who applied to various organizations seeking help against violence was diagnosed with PTSD. On the other hand, it is notable that some of these symptoms are never or rarely seen in some female victims of violence. For example, some studies show that female victims of violence who make use of effective methods of coping with stress, such as problem-solving, self-confident approach to life and seeking social support suffer to a lesser degree from negative symptoms that follow violence, such as low self-respect, depression and PTSD (Foa et. al., 2000; Waldrop \& Resick, 2004; Sabina \& Tindale, 2008). In addition, the structures of cognitive schemes that are found to be directly related to the use of effective methods of coping with stress are thought to affect whether these symptoms appear (Houskamp \& Foy, 1991; Foa, Cascardi, Zoeller \& Feeny, 2000). 
Cognitive schemes are defined as mental representations or rules used to conceive of the world, deal with difficult experiences, think about problems and solve them (Budak, 2000). These cognitive schemes are mental representations formed as a result of the experiences of the individual, or his/her relationships with others. They begin formation in childhood and from then on are continually shaped throughout our lives, and affect our perceptions of the world and the self in various ways. From the perspective of the schemes we have formed, these effects may be positive (adaptive) or negative (non-adaptive) (Calvete, Estevez and Corral, 2007). Previous studies show that anger, guilt, disengagement, and use of non-effective ways of coping are related to negative schemes, and their presence may result in symptoms of depression, an insufficient problem solving ability, and PTSD (Foa et al., 2000; Benight \& Bandura, 2004; Calvete, Estevez and Corral, 2007). On the other hand, a balanced perception of the world, perception of control, and use of effective ways of coping are found to be related to positive schemes, and that their presence contributes to psychological health (Foa et al., 2000). Another concept thought to be related to positive cognitive schemes and considered to be an important self resource is coping self-efficacy (Benight \& Bandura, 2004; Hulberti \& Morison, 2006).

Coping self-efficacy is defined as the self-belief of the individual that he or she can respond in effective ways to threatening environments or situations (Bandura, 1997; Benight \& Harper, 2002; Johnson \& Benight, 2003; Benight, Harding-Taylor, Midboe \& Durham, 2004; Benight \& Bandura, 2004; Hulberti \& Morrison, 2006). In the context of domestic violence, coping self-efficacy is defined as a very important self resource that enables women subjected to violence to avoid suffering psychological difficulties and to choose and use more effective ways of coping, referred to as domestic violence coping self-efficacy (Benight \& Bandura, 2004). The concept of domestic violence coping self- efficacy is conceptualized as the perception of women regarding their ability to deal with the trauma they experience in the aftermath of violence during post-traumatic healing process (Benight \& Bandura, 2004). On the basis of these definitions and views, Benight, Harding-Taylor, Midboe and Durham (2004) developed the Domestic Violence Coping Self-Efficacy (DV-CSE) measure, which aims to measure women's levels of coping self-efficacy following the latest attack. When they are responding to the scale, women who have been victims of violence self-evaluate their levels of coping self efficacy concerning the situations, thoughts and/or emotions stated in each item. Items of the scale express feelings and situations such as anger, guilt, shame, suicidal thoughts and exclusion that may accompany the latest incidence of violence (for example: Handling feelings of hopelessness and helplessness, since the most recent assault). 
Also, the DV-CSE Measure contains many behaviors required in the post-violence healing process. Use of this measurement tool in institutions serving women who have been victims of violence would help them focus on women's strengths, and these institutions would be able to structure their psychological counseling in consideration of the items on the measure.

In addition, school counselors provide help for many students who experience the negative consequences of domestic violence occurring in their home between their parents. Some students experience psychological, and as a result, academic difficulties at school due to violence faced by their mothers. In such cases, school counselors provide guidance and psychological counseling both for the students and their parents. It is important that, in their sessions with mothers who have been victims of violence, school counselors focus on ways of coping with stress and how to strengthen self resources, not on the stress itself. Thus, domestic violence coping self-efficacy can serve as an important tool helping women/mothers to deal with domestic violence more effectively, to access social resources, and even to end the relationship of violence they are in. Positive change in mothers would also have positive effects on their children's psychological health.

\section{Method}

\section{Sample}

The study for the adaptation of the DV-CSE measure to Turkish was conducted between January 2009-July 2009 with the participation of 258 volunteer women who had been subjected to any form of domestic violence within the previous six months and who had applied to the Psychological Guidance and Counseling Service of Illkkurşun School of Primary Education run by the Izmir Provincial Directorate of National Education, the Izmir Psychological Counseling Center, the Izmir Provincial Social Services Directorate of the Turkish Republic Prime Ministry Social Services and the Child Protection Agency, the Psychiatric Clinic of Karşıaka State Hospital, the Women's Solidarity Center of Gaziemir Municipality, the Çamdibi Women's Solidarity Center of Bornova Municipality, the Psychiatric Clinic of Alsancak State Hospital, and the Women's Solidarity Association.

The DV-CSE-T measure was applied by the researcher personally to women who ask for assistance from the Psychological Guidance and Counseling Service of Ilkkurşun School of Primary Education, the Izmir Psychological Counseling Center, and the Gaziemir Women's Solidarity Center. The researcher also provided psychological 
guidance and counseling in these institutions to women who had been victims of violence. In addition, the researcher contacted women who had been victims of domestic violence via seminars organized by various institutions and via home visits. In the rest of the institutions, the DV-CSE-T measure was applied by psychologists / psychological counselors or social workers serving in those institutions. Prior to the application of the questionnaires, the researcher met with these experts and informed them about the purpose of the study and the DV-CSE-T measure.

Research instruments

Domestic Violence Coping Self-Efficacy Measure (DV-CSE)

The "Domestic Violence Coping Self-Efficacy (DV-CSE)" Measure was developed in 2004 by Charles C. Benight, Alexandra S. Harding-Taylor, Amanda M. Midboe and Robert L. Durham for the direct measurement of cognitive schemes related to violence. The measure aims to evaluate the coping self-efficacy of women following the latest attack (see Appendix).

In the study conducted by Benight, Harding-Taylor, Midboe ve Durham (2004), the questionnaire thus developed was applied to 283 women who had sought help after being subjected to violence. All women in the sample reported that they had been victims of violence within the previous six months. A factor analysis was conducted following data collection, weak items were removed, and the final measure consisted of 29 items with a single factor. Factor loadings varied between .53 and .85. Reliability of the measure was high, as indicated by an internal consistency coefficient of .97 .

In addition, the Life Orientation Test (Scheier and Carver, 1985), the Short Psychological Well-Being Measure (Ryff, 1989), the Coping Measure (COPE) which assesses four ways of coping (active coping, seeking social support, acceptance and giving up), the Short Form of the Profile of Mood States, and the Impact of Event Measure-IES-R, which measures post-traumatic stress symptoms, were applied to the participants by the researchers. Conclusively, positive correlations were found between scores from the measure and optimism, social acceptance, active coping and psychological health. Scores from the measure were negatively correlated with trauma related stress, negative mood, and the coping method of giving up. The measure was not correlated with seeking social support. The theoretical connection between the measure and related constructs is very strong, indicating high construct validity (Benight, Taylor, Midboe \& Durham, 2004). 
The DV-CSE scale developed by Benight, Taylor, Midboe \& Durham (2004) consists of 29 items and a single dimension ("See Appendix"). Women who have been victims of violence give themselves an efficacy score of 0 to 100 for each situation described in the scale. A score of 0 indicates no self-efficacy, 50 indicates medium self-efficacy, and 100 indicates perfect self-efficacy. The overall score from the scale is calculated by taking the arithmetic mean of the scores received from individual items. The higher this score, the higher the domestic violence coping self efficacy.

\section{Procedure}

The process of the adaptation of the DV-CSE measure to Turkish started with acquiring written permission from Charles C. Benight, after which, the following procedure was followed:

In the first stage, the DV-CSE measure was translated into Turkish separately by the researcher, a psychological counseling expert, and an English teacher. A psychological counseling and guidance faculty member and the researcher compared these three translations, and the initial form of the DV-CSE-T was created by combining the best parts of these translations, making any necessary adjustments. Extra care was taken to use simple language considering that women who will respond to the scale may have low levels of education. For example, instead of psychological concepts such as trauma, stress and anxiety, non-scientific words such as pessimism, sadness and worry were used.

The initial form of the Turkish adaptation and the original measure were examined by five faculty members, each holding PhDs, one from the field of social psychology, one from clinical psychiatry and three from psychological counseling and guidance. At this stage, an important emphasis was that women who have been victims of violence in Turkey could be reluctant to share their experiences or provide information. Thus, the researcher contacted other experts who would be applying the scale (psychologists/psychological counselors, social workers), told them about the purposes of the study, and specifically asked them to emphasize privacy and anonymity issues prior to the interviews. The researcher has also prepared a written guideline on the application of the scale. The items of this guideline were as follows:

- If possible, interviews should be made face to face and no third person should be present.

- It should be clearly stated and emphasized that no names or private information will be used in the study. 
- Interviewers need to make sure that the explanation and the example that precede the scale are read.

- Interviewers need to state that they can answer only general questions and that the interviewees should respond to the items on the basis of what they make out of the wording of the item.

- Following the application of the scales, they need to be sent to the researcher as soon as possible.

The scale was originally developed for application to women who have been victims of physical violence only, and it was re-structured, after informing Charles C. Benight, to cover all types of violence (physical, sexual, emotional and economic). Interviewers and participants were specifically told that the word "attack" referred not only to physical attacks, but to verbal/and emotional attacks as well. The reason for this was the concern that Turkish women may tend to hide physical violence in particular. On the other hand, it is known that many Turkish women are victims of emotional/verbal and economic violence. Another reason for the inclusion of these violence types in the scale was to create social awareness about them as well.

In addition, the experts who assessed the DV-CSE-T scale stated that participants may have difficulty giving themselves scores in the range of 0 to 100. Accordingly, the scores for the items of the scale were restructured as follows: the option "never capable" was given a score of 0 , "rarely capable" was given a score of 1 , "sometimes capable" was given a score of 2, "often capable" was given a score of 3 , and "always capable" was given a score of 4 . Thus, the minimum score that could be received from the DV-CSE-T scale became 0 , and the maximum score became 116.

Necessary adjustments were made in line with the feedback received from the faculty members, and the pre-adaptation stage was thus completed, making the measure ready for validity and reliability analysis.

Findings and results

Validity of the DV-CSE -T measure

In this study, the process mentioned above, whereby the suitability of the DV-CSE-T scale to Turkish language and culture was assessed is also treated as an assessment of the content validity of the scale. 
To test the construct validity of the DV-CSE-T measure, factor analysis was used. The factor analysis was conducted using the Statistical Package for Social Sciences (SPSS) 13.0, over data collected from a sample of 258 participants. To examine the factor structure of the DV-CSE-T Measure, principal components analysis was used. The results of the principal components analysis showed that all items had factor loadings over .40 with the first factor. The single-dimensional solution was accepted because the theory also predicted a single-factor measure. The factor analysis was repeated using the single-dimensional structure. Factor loadings that emerged in this second factor analysis are reported in Table 1, and eigenvalues of the factors and explained variances are reported in Table 2. Figure 1 displays a graph of the eigenvalues.

Table 1: Factor Loading Values for Items of the DV-CSE-T Measure

\begin{tabular}{|c|c|}
\hline Item No & Factor \\
\hline 16 & .78 \\
\hline 14 & .72 \\
\hline 24 & .71 \\
\hline 12 & .69 \\
\hline 28 & .68 \\
\hline 19 & .67 \\
\hline 11 & .67 \\
\hline 5 & .67 \\
\hline 15 & .67 \\
\hline 20 & .66 \\
\hline 17 & .66 \\
\hline 23 & .66 \\
\hline 4 & .65 \\
\hline 21 & .65 \\
\hline 29 & .64 \\
\hline 1 & .64 \\
\hline 6 & .62 \\
\hline 25 & .62 \\
\hline 2 & .60 \\
\hline 27 & .60 \\
\hline 13 & .59 \\
\hline 7 & .58 \\
\hline 26 & .58 \\
\hline 8 & .58 \\
\hline 10 & .57 \\
\hline 9 & .55 \\
\hline 18 & .49 \\
\hline 3 & .45 \\
\hline 22 & .44 \\
\hline
\end{tabular}


Table 2: Factor Eigenvalues and Explained Variance Percentages

\begin{tabular}{llll}
\hline Factor & Eigenvalues & \% of Variance & Cumulative \% \\
\hline 1 & 11.595 & 39.982 & 39.982 \\
\hline
\end{tabular}

Figure 1: Eigenvalues Graph

\section{Scree Plot}

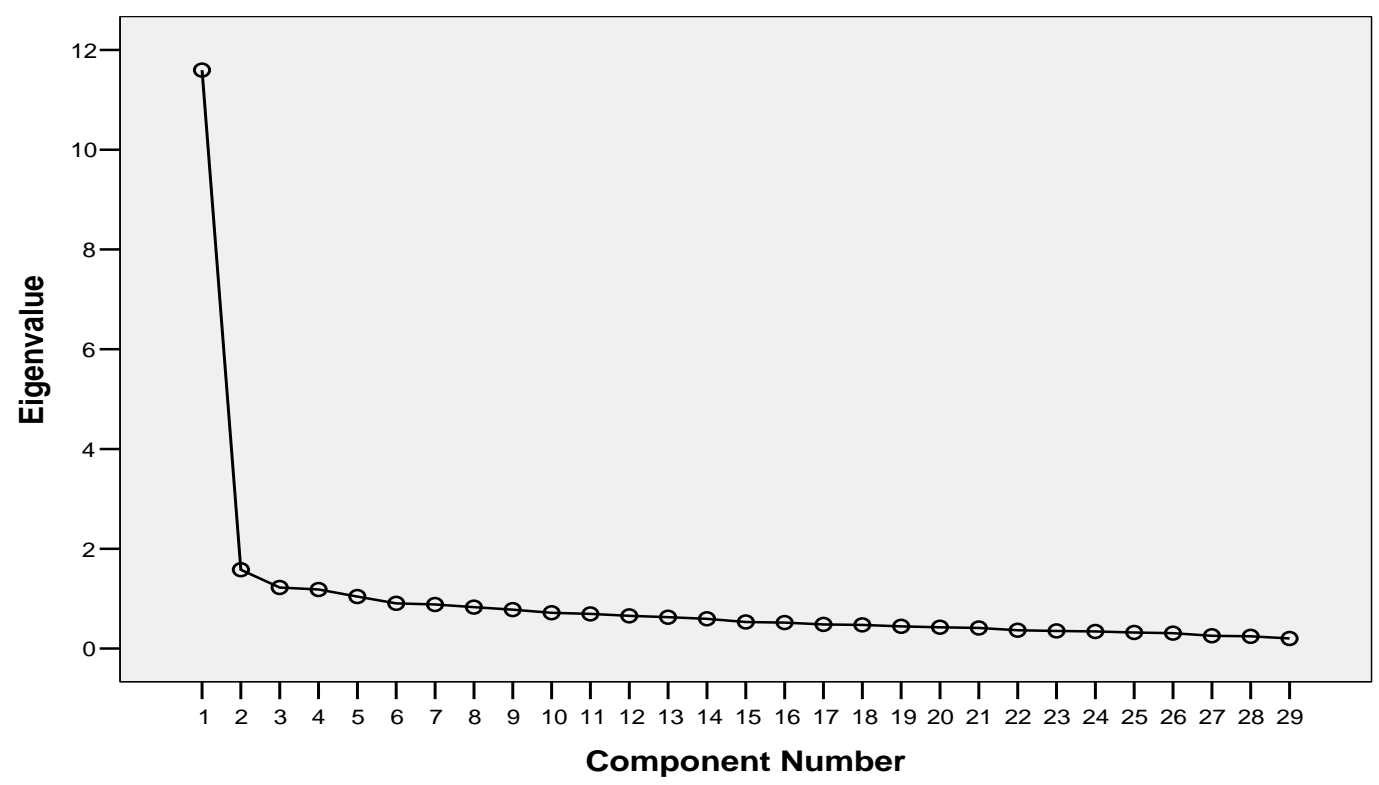

Table 1 shows that the factor loadings of all items of the measure with the first factor are .44 and above. This finding indicates that the measure has a single general factor. Table 2 shows that the first factor explains $40 \%$ of the total variance. Considered together, the variance explained and the factor loadings of the items with the first factor show that the Turkish adaptation of the DV-CSE-T is singledimensional, which is consistent with the original. This result is considered as an indication of the construct validity of the measure.

To gather evidence on the construct validity of the DV-CSE-T Measure, this study used confirmatory factor analysis. Confirmatory factor analysis is a method that allows testing of a previously formed hypothesis or theory concerning the relationship between variables. This method explores whether there is a fit or high correlation between different variables and the factors identified in the exploratory factor analysis (Kyle, 1999).

In light of this information, a confirmatory factor analysis was conducted using the LISREL 8.51 program on the basis of the single-dimensional model consisting of the 29 
items in the Turkish adaptation of the DV-CSE Measure. The results of the confirmatory factor analysis for the single dimension showed that the Chi-square value was significant at the $p<.01$ level of significance $\left(\chi^{2}=757.24, \mathrm{df}=374\right)$. The ratio between the chi-square value and the degrees of freedom was smaller than three, which indicates an acceptable level of fit (Şimşek, 2007). An examination of the fitness values of the measurement model in question showed that the GFI value was .98, the AGFI value was .98, the CFI value was .96 and the RMSA value was 0.065. The GFI, AGFI, and CFI values found indicate a good level of fitness, and the RMSA value indicates an acceptable level of fitness (Şimşek, 2007). The path diagram that contains the standard values of the confirmatory factor analysis is shown in Figure 2.

Figure 2: Path Diagram of the Confirmatory Factor Analysis for the DV-CSE-T



In conclusion, the results of the factor analysis conducted showed that the DV-CSE-T Measure has high construct validity. 
Reliability of the DV-CSE- T Measure

Reliability analysis was conducted to see if the items on a measure represent a homogenous structure (Kalaycl, 2005). The reliability of the DV-CSE-T measure was examined using the internal consistence coefficient and structural reliability calculations.

Internal consistency refers to the ratio of the sum of the variances of individual items on a measure to overall variance. This resulting figure, which varies between 0 and 1 , is referred to as Cronbach's Alpha coefficient. The Cronbach's Alpha coefficient thus calculated is a measure of the similarity of or proximity between the items on a measure, for measures in which the total score is calculated as the sum of the scores for each question (Kalaycl, 2005). The analysis conducted showed that the Cronbach's Alpha coefficient of the DV-CSE-T Measure was .94.

The other method used to examine the reliability of the measure was structural reliability calculation. McDonald's Omega $(\omega)$ coefficient was calculated using the results of the confirmatory factor analysis, which was found to be .99 for the DV-CSE-T Measure. These values provide good evidence as to the internal consistency and structural reliability of the measure.

Factor loadings ( $(\lambda \mathrm{i}), \mathrm{R}^{2}$ values and Cronbach's Alpha and Omega values on the basis of the results of the confirmatory factor analysis for the DV-CSE-T are reported in Table 3.

Table 3: Factor Loadings and $\mathrm{R}^{2}$ According to the Results of the Confirmatory Factor Analysis, Cronbach's Alpha, and McDonald's Omega Values of the DV-CSE-T

Measure

\begin{tabular}{lllll}
\hline Item & $\lambda \mathbf{i}$ & $\mathbf{R}^{2}$ & $\mathbf{a}=.94$ & $\boldsymbol{\omega}=.99$ \\
\hline 1 & .75 & .39 & & \\
2 & .78 & .33 & & \\
3 & .61 & .19 & \\
4 & .85 & .41 & \\
5 & .86 & .43 & \\
6 & .83 & .37 & \\
7 & .76 & .32 & \\
8 & .81 & .32 & \\
9 & .75 & .29 & \\
10 & .78 & .32 & \\
11 & .87 & .44 &
\end{tabular}




\begin{tabular}{lll}
12 & .92 & .46 \\
13 & .79 & .33 \\
14 & .98 & .52 \\
15 & .92 & .41 \\
16 & 1.02 & .60 \\
17 & .88 & .42 \\
18 & .66 & .23 \\
19 & .87 & .44 \\
20 & .90 & .43 \\
21 & .78 & .40 \\
22 & .56 & .19 \\
23 & .92 & .41 \\
24 & .87 & .49 \\
25 & .82 & .37 \\
26 & .79 & .32 \\
27 & .80 & .34 \\
28 & .90 & .42 \\
29 & .87 & .40 \\
\hline
\end{tabular}

\section{Conclusion and future perspectives}

The results of the study show that the Turkish adaptation of the DV-CSE Measure consists of a single factor that measures domestic violence coping self-efficacy, and that the figures associated with the measure are at sufficient levels in terms of psychometric characteristics. Most of the studies on domestic violence against women focus on the pervasiveness of domestic violence, and the physical and psychological effects it has on women. Qualitative and quantitative studies to be conducted in the future on domestic violence coping self- efficacy would bring a fresh perspective to the issue of domestic violence, and make important contributions to the literature on the subject.

From another angle, experimental studies that would complement the descriptive studies on domestic violence coping self-efficacy would make an important contribution to the practice of psychological counseling and guidance. Experimental studies on the effectiveness of group psychological counseling and psychological training on improving the coping self-efficacy of female victims of domestic violence, and use of programs scientifically shown to be effective in institutions serving women who have been victims of violence would improve the overall quality of the services offered. Thus, the use of the DV-CSE-T in institutions serving women who have been victims of violence can help identify the strengths of these women, and can contribute to the development of support programs against 
violence. In particular, it can help answer, even if only partially, the question "what makes a victim of violence strong?". From another angle, the DV-CSE-T scale avoids focusing solely on physical violence, which can help create an awareness that violence may come in different forms, such as in the form of emotional/verbal, sexual or economic violence, and that it is necessary and possible to deal with these forms as well.

Moreover, this study had a number of limitations. Women who have been victims of violence in Turkey may still be reluctant to share the violence they faced. Even when they seek help from various institutions themselves, women may be worried that they might face violence by their husbands again, which makes it difficult to collect data on domestic violence. The sample of this study consisted of female victims of violence who lived in or around Izmir, due both to the difficulties associated with data collection and time limitations. In addition, no demographic information (age, level of education, socio-economic status, etc.) was collected about the participants due to anonymity concerns.

The validity of the DV-CSE-T scale was examined in this study via an assessment of the content and construct validity only. Using other validity analyses such as criterion validity, convergent validity and discriminant validity with larger samples, future studies may create new versions of the DV-CSE-T scale.

The sample of this study consisted of women who applied to various institutions due to domestic violence. Yet, it is known that many women who are victims of violence avoid taking this step, and we have insufficient information on how these women cope with the violence they face. Thus, future studies could provide more and comprehensive information on domestic violence by contacting women who have been victims of violence but who did not apply to any institution seeking help. Comparative studies on the coping self-efficacy of female victims of domestic violence who apply and do not apply to various institutions, on the other hand, could make an important contribution to the literature on domestic violence.

\section{References}

Amnesty International (2004). Kadına yönelik şiddet sayacı-istatistiki bilgiler-özet. [The counter of violence against woman-statistical information-summery]. Retrieved July 2010 from http://www.amnesty.org.tr/ 
Altınay, A.G. ve Arat, Y. (2008). Türkiye'de kadına yönelik şiddet [Violence agains†' women in Turkey]. İstanbul: Punto Baskı Çözümleri.

Bandura, A. (1997). Self-efficacy. Harvard Mental Health Letter. 13(9).

Benight, C.C. ve Harper, M.L. (2002). Coping self-efficacy perceptions as a mediator between acute stress response and long-term distress following natural disasters. Journal of Traumatic Stress, 15, 177-186.

Benight, C.C. \& Bandura, A. (2004). Social cognitive theory of posttraumatic recovery: the role perceived self-efficacy. Behaviour Research and Therapy, 42, 1129-1148.

Benight, C.C., Harding-Taylor, A.S., Midboe, A.M. \& Durham, R.L. (2004). Development and psychometric validation of a domestic violence coping self-efficacy measure (DVCSE). Journal of Traumatic Stress, 17, 505-508.

Budak, S. (2000). Psikoloji sözlüğü [Psychology dictionary]. Ankara: Bilim ve Sanat Yayınları.

Calvete, E., Estevez, A. \& Corral, S. (2007). Posttraumatic stress disorder and its relationship with negative cognitive schemas in battered women. Psicothema, 19, 446451.

Cieslak, R., Benight, C.C. \& Caden, L.V. (2008). Coping self-efficay mediate the effect of negatif cognitions on postraumatic distress. Journal of Behaviour Research and Therapy, 46, 788-798.

Clements, C.M., Sabourin, \& Spiby, L. (2004). Dysphoria and hopelesness following battering: the role of perceived control, coping and self-esteem. Journal of Family Violence, 19 (1).

Damka, Z. (2009). Sığınma evinde kalan şiddet mağduru kadınlar: anksiyete duyarlığı, travmaya bağlı suçluluk, travma sonrası stres bozukluğu ve psikolojik belirtiler [Sheltered battered women: anxiety, sensitivity, trauma related guilt, posttraumatic stress disorder and psychological symptoms]. Unpublished master's dissertation, Ankara Üniversitesi Sosyal Bilimler Enstitüsü, Ankara.

Foa, E.B., Cascardi, M. Zoeller, L.A.\& Feeny, N.C. (2000). Psychological and environmental factors associated with partner violence. Trauma, Violence ve Abuse, 1 , 67-91. 
Gleason, W.J. (1993). Mental disorders in battered women: an empirical study. Violence and Victims, 8, 53-68.

Heise, L. (1993). Violence against women the hidden health burden. World Health Statistics Quarterly, 46.

Houskamp, B.M. \& Foy, D.W. (1991). The assessment of posttraumatic stress disorder in battered women. Journal of interpersonal Violence.

Hulberti, N.J. \& Morrison, V.L. (2006). A preliminary study into stress in paliative care: optimism, self efficacy and social support. Psychology, Health ve Medicine, 11, 246-25

ICN (2001). Nurses, always there for you: United against violence. International Nurses Day 2001. Anti-Violence Tool Kit.

Johnson, L.E. ve Benight, C.C. (2003). Effects of trauma-focused research on recent domestic violence survivors. Journal of Traumatic Stress, 16, 567-571.

Kalaycı, Ş. (Ed.). (2005). SPSS uygulamalı çok değişkenli istatistik teknikleri [Multivariate statistical techniques SPSS applied]. Ankara: Asil Yayın Dağııım Ltd.

Korkut-Owen, F.\& Owen, W. (2008). Kadına yönelik aile içi şiddet. [Domestic violence against woman]. Retrieved July 2009 from http://www.aileicisiddet.net/ Kyle, R. (1999). Basic concepts of confirmatory factor analysis. Educational Research Association, 21-23.

Perez, I.R., Castano, J.P.\& Lozano, M.R. (2007). Physical health consequences of intimate partner violence in spanish women. Journal of Public Health, 17, 437-443.

Sabina, C.\& Tindale, R.S. (2008). Abuse charasteristics and coping resources as predictors of problem-focused coping strategies among battered women. Violence Against Women, 14, 437-56.

Saunders, D.G. (1994). Posttraumatic stres symptom profiles of battered women: a comparison of survivors in two setting. Violence and Victims, 9 (1).

Şimşek, Ö.F (2007). Yapısal eşitlik modellemesine giriş: Temel ilkeler ve lisrel uygulamaları [Introduction to basic principles of structural equation modeling and lisrel applications]. Ankara: Ekinoks Yayıncilık. 
Türkiye'de Kadına Yönelik Aile içi Şiddet Araştırması (2008). [National research on domestic violence against women in turkey 2008]. T.C. Başbakanlık Kadının Statüsü Genel Müdürlüğü, Hacettepe Üniversitesi Nüfus Etütleri Enstitüsü, ICON-Institut Public Sector GmbH and BNB Danışmanlık (2009).

Waldrop, A.E.\& Resick, P.A. (2004). Coping among victims of domestic violence. Journal of Family Violence, 19 (5).

WHO (2002). World report on violence and health, Genova. 


\section{Appendix - Items of The Domestic Violence Coping Self Efficacy (DV-CSE) Measure (Original Form)}

1. Feeling good about myself, since the most recent assault.

2. Managing feelings of grief, loss and abandonment after the latest attack.

3. Managing my housing, food, clothes and medical needs, since the most recent assault.

4. Managing feelings of depression and/or suicidal thoughts, since my partner attacked me.

5. Handling feelings of hopelessness and helplessness, since the most recent assault.

6. Controlling thoughts that I am going crazy, since my latest assault.

7. Managing my feelings of guilt and self-blame about the abuse.

8. Handling fears of being alone after the latest assault.

9. Handling feelings of anger/rage at my partner, since the most recent assault.

10. Managing my desire to have closure of my relationship with the abuser.

11. Controlling feelings of anxiety and panic after the latest assault.

12. Coping with loneliness and isolation, since the most recent attack.

13. Dealing with nightmares/flashbacks concerning the latest assault.

14. Thinking that I am a competent woman, since the most recent assault.

15. Dealing with feelings of shame concerning the abuse.

16. Coping with feeling completely overwhelmed with everything, since the most recent assault.

17. Being able to concentrate and effectively handle my home, job and parenting responsibilities.

18. Dealing with my anxiety about the future without my partner.

19. Controlling thoughts that "I just can't handle this."

20. Being strong emotionally for my family and friends.

21. Managing my own spiritual pain, since the most recent assault.

22. Trusting anyone.

23. Coping with my appearance, since the most recent assault.

24. Dealing with feelings of sadness.

25. Controlling negative thoughts about myself (for example "I am stupid", "I am to blame", "I am a loser", "I screw-up everything", "I deserved to be attacked").

26. Coping with loss of the "good" aspects of my relationship with the man who assaulted me.

27. Coping with the feelings that family and friends just don't understand.

28. Handling feelings of embarrassment.

29. Dealing with rejection from others. 
About the author:

Orkide Akpınar had graduated from Dokuz Eylül University (İzmir, Turkey), Guidance and Psychological Counseling Dept. She had master's degree at Ege University (Izmir, Turkey) in Guidance and Psychological Counseling. She obtained her Ph.D degree at Ege University in same dept. At the same time she works at a public primary school in Izmir as a school counselor. Psychodrama and stress coping are also among her main interests.

Address for Correspondence: Orkide Akpınar, İlkkurşun İlköğretim Okulu, 4539 sk. No: 10 Yeni Çamlık / IZMMiR

E-mail: orkide1605@gmail.com 